\title{
Sexual Function in Females With Rheumatoid Arthritis: Relationship With Physical and Psychosocial States
}

\author{
Essam ABDA, ${ }^{1}$ Zahra SELIM, ${ }^{1}$ Samia TELEB,${ }^{2}$ Mahmoud ZAGHIRA, ${ }^{3}$ \\ Mohamed FAWZY, ${ }^{4}$ Sherifa HAMED ${ }^{4}$ \\ ${ }^{1}$ Department of Rheumatology and Rehabilitation, Assiut University Hospital, Assiut, Egypt \\ ${ }^{2}$ Assiut University, Faculty of Nursing, Assiut, Egypt \\ ${ }^{3}$ Department of Obstetrics and Gynecology, Assiut University Hospital, Assiut, Egypt \\ ${ }^{4}$ Department of Neurology and Psychiatry, Assiut University Hospital, Assiut, Egypt
}

\begin{abstract}
Objectives: This study aims to assess the frequency rates of sexual problems and associated factors in a cohort of married females with rheumatoid arthritis (RA).

Patients and methods: The study included 200 female RA patients (mean age $44.2 \pm 9.1$ years; range 18 to 55 years) and 100 age matched healthy control females (mean age $42.5 \pm 6.3$ years; range 18 to 55 years). Mean duration of RA was $5.8 \pm 4.1$ years. All participants were assessed by Health Assessment Questionnaire Disability Index, Numerical Rating Pain Scale, Sexual Disability Scale, psychiatric interview, Beck Depression Inventory, and Spielberger's State-Trait Anxiety Inventory.

Results: Majority of the patients had grade II physical disability (62\%), moderate pain (55\%), depression (46\%), and anxiety (77\%). Sexual disability and loss of sexual desire and satisfaction were reported in $4 \%$ to $77.8 \%$ of patients which varied with age, duration of RA, degree of physical disability, and psychiatric comorbidities. Multiple regression analysis showed that scores of sexual disability and loss of sexual desire and satisfaction were significantly associated with scores of Health Assessment Questionnaire Disability Index $(\beta=0.347 ; p=0.018 ; \beta=0.501 ; p=0.001)$ and depression $(\beta=0.304 ; p=0.043 ; \beta=0.550 ; p=0.001)$.

Conclusion: We may conclude that the frequencies of sexual problems in females with RA are high and closely related to physical disability and psychiatric comorbidities.

Keywords: Rheumatoid arthritis; sexual problems; physical disability; depression; anxiety.
\end{abstract}

Rheumatoid arthritis (RA) is an inflammatory multi-system connective tissue disorder affecting joints with an approximated prevalence of $0.5 \%$ to $1 \%$ in Northern European and North American white populations, and a mean annual incidence of $0.02 \%$ to $0.05 \% .{ }^{1}$ Furthermore, reports from Africa note an increasing incidence; e.g. in Egyptian population, the prevalence of RA is approximately $0.3 \% .^{2}$ RA inevitably leads to pain, various degrees of disability, and profound impact on individual's physical, psychological, and socioeconomic aspects of life.
Sexuality is a complex aspect of the human's life and is more than the sexual act only. Sexual activity has an impact on sexual satisfaction of patients, several aspects of their personal lives and relationships. Normal sexual functioning consists of sexual activity with transition through the phases from arousal to relaxation with no problems, and with a feeling of pleasure, fulfillment, and satisfaction. Patients with RA experience different aspects of sexual problems such as difficulties in sexual performance and diminution of sexual desire, arousal, lubrication, 
orgasm and satisfaction, which are directly or indirectly caused by the disease..$^{3-10}$ The cause of sexual problems with RA is multifactorial due to chronic disease aspects such as disease activity, pain, reduced physical activities, fatigue, and poor sleep and psychiatric comorbidities such as depression, anxiety, poor self-esteem, and altered body image and rarely drugs used for treatment. ${ }^{8,11-13}$ Researches are needed to identify and understand the mechanisms of sexual problems in RA to determine different types of interventions to support a satisfactory quality of life for patients with RA.

Data from studies on sexual function in patients with RA are limited. Therefore, in this study, we aimed to assess the frequency rates of sexual problems and associated factors in a cohort of married females with RA.

\section{PATIENTS AND METHODS}

This cross-sectional analytical study included 200 female RA patients (mean age 44.2 \pm 9.1 years; range 18 to 55 years) and 100 age matched healthy control females (mean age $42.5 \pm 6.3$ years; range 18 to 55 years) recruited from the general population. RA diagnosis was established according to the revised criteria of American College of Rheumatology for $\mathrm{RA}^{14}$ at least two years before participation in the study. All participants were sexually active with stable and long-lasting relationships. Patients had different classes and stages of the disease and were recruited during the course of their regular appointments in the out-patient clinic of the Department of Rheumatology and Rehabilitation of our University Hospital (Tertiary Care). The patients were only receiving disease-modifying anti-rheumatic drugs which included one or more of the following: methotrexate, hydroxychloroquine, colchicine, corticosteroids, and non-steroidal antiinflammatory drugs. Corticosteroids and nonsteroidal anti-inflammatory drugs were used in short-courses to relieve pain. None of the patients was receiving a biological treatment as all had low socioeconomic status and education level and their insurance could not afford biological treatments. Control subjects were also matched for socioeconomic and educational levels. This study was accepted by the regional ethics committee.
Detailed information on the study was given to all participants and written informed consent was obtained from each participant. The study was conducted in accordance with the principles of the Declaration of Helsinki. Exclusion criteria were: (i) communicative disorders as deafness, blindness and mental retardation, (ii) gynecological disease or abnormalities that can influence sexuality as cervical cyst, abnormal pap smear, ovarian cyst, uterine prolapses, Bartholin's cyst and vulvovaginal ulcer, (iii) psychiatric or systemic medical or endocrine disease that may disturb sexual or reproductive function, and (iv) use of chronic medications other than those for RA that may affect the normal reproductive or sexual function.

All participants underwent complete rheumatologic, medical, neurologic, psychiatric, and gynecologic evaluations. Clinical variables of disease activity include the count of swollen and tender joints and a modification of the composite index of disease activity. ${ }^{15}$ Gynecological assessment included detailed medical history and speculum examination, bimanual and rectovaginal examination, and pap-smear. Vaginal ultrasound examination was performed to exclude pelvic pathology using trans-vaginal probe $5 \mathrm{MHz}$ (angle 60 degrees) (ALOKA, echocamera-SSD, ALOKA Corporation, Tokyo, Japan). Routine hematological tests were conducted including erythrocyte sedimentation rate, C-reactive protein, complete blood count, blood sugar (fasting and post-prandial), renal and liver functions, and rheumatoid factor.

An Arabic version of the Health Assessment Questionnaire Disability Index (HAQ-DI) ${ }^{16}$ was used to measure the subject's level of functional ability in daily activities and utility of usual equipment over the past week. The HAQ-DI is regularly used in rheumatology research and has been used in studies concerning sexual health and RA. ${ }^{17}$ Correlations between interview and questionnaire format ranged from 0.85 to 0.95 . Correlations between questionnaire or interview scores and task performance ranged from 0.71 to 0.95 demonstrating criterion validity. The HAQ-DI is composed of 20 items. There are eight categories, each of which has at least two component questions: (i) dressing and grooming, (ii) arising, (iii) eating, (iv) walking, (v) hygiene, (vi) reach, (vii) grip, and (viii) common daily 
activities as shopping. For each of the categories, patients report the amount of difficulty they have in performing two or three specific sub-category items or component variables. There are four possible responses for each sub-category item or component within a category: $0=$ without any difficulty, $1=$ with some difficulty, $2=$ with much difficulty, $3=$ unable to do.

As the included patients were either illiterate or only knew how to read and write, we used the numerical rating scale (NRS) as it was shown to be more reliable than the visual analog scale in literate patients as well as illiterate patients. ${ }^{18}$ We did not use the disease activity score in 28 joints as its calculation depends on entering the following data: tender joint count (0-28), swollen joint (0-28), erythrocyte sedimentation rate, and visual analog scale. In NRS, patients related their pain on the day of the interview numerically on a scale from 0 to 10 . NRS is conceptualized in the following manner: $0=$ no pain, $1-3=$ mild pain (nagging, annoying, interfering little with activities of daily living), 4-6= moderate pain (interferes significantly with activities of daily living) and 7-10 = severe pain (disabling; unable to perform activities of daily living).

A questionnaire for assessing sexual disability and desire or satisfaction was derived from the original HAQ. ${ }^{19}$ Sexual disability during the previous month was inquired and scored into four ascending scores from complete ability to complete inability to engage in sexual intercourse (0-3), while loss of sexual desire or satisfaction was scored from 0-4.

Standardized psychiatric interview was performed by applying the Diagnostic and Statistical Manual of Mental Health Disorders, fourth edition criteria. ${ }^{20} \mathrm{~A}$ differentiation between clinical depression and anxiety and depressive and anxiety symptoms was conducted within the scope of this work. The Arabic version ${ }^{21}$ of the Beck Depression Inventory $(\mathrm{BDI}-\mathrm{II})^{22}$ was used for the assessment of the severity of depression symptoms. BDI-II consists of 21 items, each corresponding to a symptom of depression to be summed to give a single score. According to this scale, the patient may have no symptoms or have minimal symptoms (scoring: 0-13), mild symptoms (scoring: 14-19), moderate symptoms (scoring: 20-28), or severe symptoms (scoring: 29-63).
Spielberger's State-Trait Anxiety Inventory was used to examine anxiety levels in RA patients as a self-report. This inventory consists of 20 items questioning how a person feels now and reflects situational factors that may influence anxiety levels. Answers are scored on a scale of 1 to 4 and scores range from 20 to 80 . Levels of anxiety are classified into three levels according to scores: average (27-35), above average (36-51), or severe $(52-80) .{ }^{23}$

\section{Statistical analysis}

All data were statistically processed with the SPSS for Windows, version 12.0 software (SPSS Inc., Chicago, IL, USA). Data are expressed as mean \pm standard deviation. For the analysis of categorical data, the Chi-square was used. Independent twosided Student's t test was used for comparison of the means of normally distributed measures and Mann-Whitney U test was used for comparison of the means of not normally distributed measures. Pearson's correlation coefficient was used to assess correlations for normally distributed data while Spearman's coefficient was used for nonnormally distributed data. Multivariate analysis was applied to determine the correlations between sexual disability and loss of sexual desire and satisfaction and age, duration of RA, scores of disease activity, HAQ-DI, NRS, depression and anxiety. The model was adjusted for age and duration of RA as confounder. For all tests, values of $p<0.05$ were considered statistically significant.

\section{RESULTS}

Mean disease duration was $5.8 \pm 4.1$ years. The majority of the patients had knee (74\%) and hip (69\%) joints involvement. The demographic and clinical characteristics of the study group are shown in Table 1. For comparisons, patients were divided into groups according to age at presentation ( 20 to $<40$ and $\geq 40$ to 55 years old) and duration of $\mathrm{RA}(<2$ and $\geq 2$ years). Table 2 shows the results of physical function disability (HAQ-DI) among the patients with RA. According to the HAQ-DI, the majority had difficulty in dressing (43\%), arising (22\%) and reach (22\%). Canes (9\%) and wheelchairs (4\%) were the aids frequently used for activities. The majority of patients had grade II physical disability (62\%), moderate pain (55\%), depression (46\% compared to $11 \%$ in controls; 


\begin{tabular}{|c|c|c|c|c|}
\hline & $\mathrm{n}$ & $\%$ & Mean \pm SD & Range \\
\hline Age (years) & & & $44.2 \pm 9.1$ & $23-55$ \\
\hline Duration of marriage (years) & & & $18.5 \pm 3.5$ & 3-37 \\
\hline \multicolumn{5}{|l|}{ Degree of education } \\
\hline Illiterate & 164 & 82 & & \\
\hline Read and write & 36 & 18 & & \\
\hline Duration of illness (years) & & & $5.8 \pm 4.1$ & $1.5-17$ \\
\hline \multicolumn{5}{|l|}{ Disease activity } \\
\hline Number of swollen joints & & & $5.9 \pm 3.5$ & \\
\hline Number of tender joints & & & $5.3 \pm 2.9$ & \\
\hline Index of disease activity & & & $2.5 \pm 0.5$ & \\
\hline Morning stiffness (minutes) & & & $88.2 \pm 52.0$ & \\
\hline Erythrocytic sedimentation rate $(\mathrm{mm} / \mathrm{h})$ & & & $53.3 \pm 20.3$ & \\
\hline C-reactive protein & & & $30.3 \pm 11.3$ & \\
\hline Ritchie articular index & & & $27.0 \pm 7.2$ & \\
\hline Rheumatoid factor & & & $32.5 \pm 4.3$ & \\
\hline Knee joint involvement & 148 & 74 & & \\
\hline Hip joint involvement & 138 & 69 & & \\
\hline \multicolumn{5}{|l|}{ Treatment } \\
\hline Methotrexate and nonsteroidal antiinflammatory drugs & 65 & 32.50 & & \\
\hline Steroids & 40 & 20 & & \\
\hline Nonsteroidal antiinflammatory drugs & 69 & 34.45 & & \\
\hline Colchicine & 2 & 1.00 & & \\
\hline Methotrexate and hydroquinone & 24 & 12 & & \\
\hline \multicolumn{5}{|l|}{ Groups of patients according to the age at presentation } \\
\hline 18-39 years old & 146 & 73 & & \\
\hline 40-55 years old & 54 & 27 & & \\
\hline \multicolumn{5}{|l|}{ Groups of patients according to the duration of illness } \\
\hline$<2$ years & 36 & 18 & & \\
\hline$\geq 2$ years & 164 & 82 & & \\
\hline
\end{tabular}

$\mathrm{p}<0.0001)$ and anxiety $(77 \%$ compared to $25 \%$ in controls; $p<0.0001$ ) while none of the patients was without disability or pain. Sexual disability and loss of sexual desire and satisfaction were reported in $4 \%$ to $77.8 \%$ of patients (compared to $3 \%$ to $20 \%$ of controls), varying with age, duration of RA, degree of physical disability, pain and psychiatric comorbidities such as depression and anxiety. Table 3 shows the relationship between patient's age, duration of RA and the sexual disability and loss of sexual desire. It was observed that as the age and disease duration of patients increased, the number of sexually disabled patients increased. Table 4 shows the relationship between physical function and sexual disability and psychiatric manifestations. It was observed that as the number of patients with severe physical disability increased, the number of patients with sexual disability, depression and anxiety increased. Univariate regression showed that scores of sexual disability and loss of sexual desire and satisfaction were positively associated with age $(p=0.039 ; p=0.043)$, duration of RA ( $p<0.001$ for both), index of disease activity $(p<0.001 ; p=0.052)$, scores of HAQ-DI $(p=0.001 ;$ $p=0.032)$, NRS ( $p=0.007 ; p=0.025)$, depression $(p<0.001$ for both) and anxiety $(p<0.001$ for both). In multiple regression analysis and after adjustment for confounding factors (age and duration of RA), scores of sexual disability and loss of sexual desire and satisfaction were associated with scores of HAQ-DI $(\beta=0.347 ; p=0.018$; $\beta=0.501 ; p=0.001)$ and depression $(\beta=0.304$; $p=0.043 ; \beta=0.550 ; p=0.001)$ but not with scores of index of disease activity or NRS.

\section{DISCUSSION}

Rheumatoid arthritis is a debilitating disease causing chronic pain, stiffness, and swelling of joints and physical disability which may severely impede patients' functioning and emotional wellbeing. In this study, we assessed the magnitude of sexual dysfunction in a cohort of females with RA and determined the factors related to sexual problems. Only females were included due to the limited number of males recruited 


\begin{tabular}{|c|c|c|c|c|}
\hline & $\mathrm{n}$ & $\%$ & Mean \pm SD & Range \\
\hline \multicolumn{5}{|l|}{ Physical function disability (HAQ-DI) } \\
\hline HAQ-DI score & & & $1.6 \pm 0.6$ & \\
\hline Duration of physical disability (years) & & & $6.5 \pm 4.3$ & 1.8-17 \\
\hline \multicolumn{5}{|l|}{ Help from another person for the followings } \\
\hline Dressing & 86 & 43 & & \\
\hline Arising & 44 & 22 & & \\
\hline Eating & 28 & 14 & & \\
\hline Walking & 8 & 4 & & \\
\hline Hygiene & 26 & 13 & & \\
\hline Reach & 44 & 22 & & \\
\hline Gripping and opening thing & 28 & 14 & & \\
\hline Shopping & 8 & 4 & & \\
\hline \multicolumn{5}{|l|}{ Aids usually used for activities } \\
\hline Cane & 18 & 9 & & \\
\hline Walker & 0 & 0 & & \\
\hline Crutches & 0 & 0 & & \\
\hline Wheelchair & 8 & 4 & & \\
\hline \multicolumn{5}{|l|}{ Grading of physical function (HAQ-DI) } \\
\hline Grade 0 (without difficulty) & 0 & 0 & & \\
\hline Grade I (with some difficulty) & 52 & 26 & & \\
\hline Grade II (with much difficulty) & 124 & 62 & & \\
\hline Grade III (unable to do) & 24 & 12 & & \\
\hline \multicolumn{5}{|l|}{ Numerical Rating Pain Scale } \\
\hline Numerical rating scale score & & & $5.2 \pm 0.8$ & \\
\hline Duration of pain (years) & & & $5.8 \pm 4.1$ & $1.5-17$ \\
\hline No pain & 0 & 0 & & \\
\hline Mild pain & 15 & 7.5 & & \\
\hline Moderate pain & 110 & 55 & & \\
\hline Severe pain & 75 & 37.5 & & \\
\hline \multicolumn{5}{|c|}{ Sexual disability and loss of sexual desire or satisfaction } \\
\hline Duration of sexual problems (years) & & & $8.4 \pm 5.6$ & $2.5-15$ \\
\hline Sexual disability score & & & $1.3 \pm 0.4$ & \\
\hline \multicolumn{5}{|l|}{ Grading of sexual disability } \\
\hline Grade 0 (able) & 42 & 21 & & \\
\hline Grade I (mild) & 90 & 45 & & \\
\hline Grade II (moderate) & 34 & 17 & & \\
\hline Grade III (complete unable) & 34 & 17 & & \\
\hline Loss of sexual desire or satisfaction & & & $1.8 \pm 0.6$ & \\
\hline \multicolumn{5}{|l|}{ Grading of loss of sexual desire or satisfaction } \\
\hline Grade 0 (never) & 18 & 9 & & \\
\hline Grade I (rarely) & 8 & 4 & & \\
\hline Grade II (sometimes) & 108 & 54 & & \\
\hline Grade III (often) & 8 & 4 & & \\
\hline Grade IV (always) & 58 & 29 & & \\
\hline \multicolumn{5}{|l|}{ Psychiatric comorbidities } \\
\hline Duration of psychiatric comorbidities (years) & & & $6.5 \pm 3.2$ & 3.2-15 \\
\hline Depression score & & & $29.8 \pm 5.4$ & $20-40$ \\
\hline \multicolumn{5}{|l|}{ Depression degree } \\
\hline Mild & 48 & 24 & & \\
\hline Moderate & 92 & 46 & & \\
\hline Severe & 60 & 30 & & \\
\hline Anxiety score & & & $44.0 \pm 6.1$ & $28-55$ \\
\hline \multicolumn{5}{|l|}{ Anxiety degree } \\
\hline Average & 22 & 11 & & \\
\hline Above average & 154 & 77 & & \\
\hline Severe & 24 & 12 & & \\
\hline
\end{tabular}

throughout the period of study. In fact, RA is two- to three-folds more frequent in females than males. Current data suggest that females suffer greater disability than males because of
RA. ${ }^{1,10}$ In RA, sex hormones (as estrogens) in particular have recently been found to regulate the immune response by favoring the survival of forbidden autoreactive clones and genes in sexual 


\begin{tabular}{|c|c|c|c|c|c|c|c|c|c|c|c|c|c|c|}
\hline & \multicolumn{6}{|c|}{$\begin{array}{l}\text { Groups of RA according to the } \\
\text { age at presentation }\end{array}$} & \multirow[b]{2}{*}{$p$} & \multicolumn{6}{|c|}{$\begin{array}{l}\text { Groups of RA according to the } \\
\text { duration of RA }\end{array}$} & \multirow[b]{2}{*}{$p$} \\
\hline & $\mathrm{n}$ & $\%$ & Range & $\mathrm{n}$ & $\%$ & Range & & $\mathrm{n}$ & $\%$ & Range & $\mathrm{n}$ & $\%$ & Range & \\
\hline \multicolumn{15}{|l|}{ Sexual disability } \\
\hline Grade 0 (able) & 26 & 17.8 & & 16 & 26.6 & & & 18 & 50 & & 24 & $14.6)$ & & \\
\hline Grade I (mild) & 52 & 35.6 & & 38 & 70.4 & & 1 0000 & 10 & 27.8 & & 80 & 48.8 & & \\
\hline Grade II (moderate) & 34 & 23.3 & & 0 & 0 & & 0.0001 & 0 & 0 & & 34 & 20.7 & & 0.002 \\
\hline Grade III (complete unable) & 34 & 23.3 & & 0 & 0 & & & 8 & 22.2 & & 26 & 15.9 & & \\
\hline $\begin{array}{l}\text { Loss of sexual desire or } \\
\text { satisfaction }\end{array}$ & & & $18-39$ & & & $40-55$ & & & & $<2$ years & & & $\geq 2$ years & \\
\hline Grade 0 (never) & 0 & 0 & & 18 & 33.3 & & & 0 & 0 & & 18 & 11 & & \\
\hline Grade I (rarely) & 8 & 5.5 & & 0 & 0 & & & 0 & 0 & & 8 & 4.9 & & \\
\hline Grade II (sometimes) & 82 & 56.1 & & 26 & 48.1 & & 0.243 & 28 & 77.8 & & 80 & 48.8 & & 0.522 \\
\hline Grade III (often) & 8 & 5.5 & & 0 & 0 & & & 0 & 0 & & 16 & 4.9 & & \\
\hline Grade IV(always) & 48 & 32.9 & & 10 & 18.5 & & & 8 & 22.2 & & 50 & 30.5 & & \\
\hline
\end{tabular}

chromosomes. This supports the findings of higher prevalence of RA demonstrated in females than males. ${ }^{6}$ In addition, it has been reported that there are differences concerning sexual health between males and females, especially during sexual activities in which females have more difficulties than males. ${ }^{24,25}$

In this study, the majority of patients had higher scores of physical disability (62\%), pain (55\%), depression (46\%), and anxiety (77\%). Also, the majority of patients had knee (74\%) and hip (69\%) joints involvement. In general, it has been reported that $30 \%$ of females with arthritis had poor self-rated health and up to 50\% had longterm disability compared to $20 \%$ of females with other chronic condition; $43 \%$ of these patients had trouble in several tasks such as climbing stairs or opening tight jar lids and required assistance to accomplish a variety of tasks including personal care, household chores and shopping. This condition was related to the associated pain in $21 \%$ to $45 \%$ of these patients. ${ }^{26}$

In this study, we reported that up to $46 \%$ of patients had some degree of depression and up to $77 \%$ had anxiety. In general, patients with RA suffer from depression or anxiety more frequently than general population. The prevalence of depression and anxiety with RA was estimated to reach up to $66.2 \%{ }^{27-29}$ and $70 \%,{ }^{29}$ respectively. In a study of Japanese females with RA performed

\begin{tabular}{|c|c|c|c|c|c|c|c|}
\hline & \multicolumn{6}{|c|}{ Physical function (HAQ-DI) } & \multirow[b]{3}{*}{$p$} \\
\hline & \multicolumn{2}{|c|}{1} & \multicolumn{2}{|c|}{2} & \multicolumn{2}{|c|}{3} & \\
\hline & $\mathrm{n}$ & $\%$ & $\mathrm{n}$ & $\%$ & $\mathrm{n}$ & $\%$ & \\
\hline \multicolumn{8}{|l|}{ Sexual disability } \\
\hline Grade 0 (able) & 18 & 34.6 & 24 & 19.4 & 0 & 0 & \multirow{4}{*}{0.0001} \\
\hline Grade I (mild) & 18 & 34.6 & 72 & 58.1 & 0 & 0 & \\
\hline Grade II (moderate) & 8 & 15.4 & 10 & 8.1 & 16 & 66.7 & \\
\hline Grade III (complete unable) & 8 & 15.4 & 18 & 14.5 & 8 & 33.3 & \\
\hline \multicolumn{8}{|l|}{ Psychiatric comorbidity } \\
\hline \multicolumn{8}{|l|}{ Depression } \\
\hline Mild & 16 & 30.8 & 23 & 25.8 & 0 & 0 & \multirow{3}{*}{0.0001} \\
\hline Moderate & 36 & 69.2 & 48 & 38.7 & 16 & 33.3 & \\
\hline Severe & 0 & 0 & 44 & 35.5 & 32 & 66.7 & \\
\hline \multicolumn{8}{|l|}{ Anxiety } \\
\hline Average & 8 & 15.4 & 12 & 9.6 & 2 & 8.3 & \multirow{3}{*}{0.009} \\
\hline Above average & 28 & 53.8 & 106 & 85.5 & 20 & 83.3 & \\
\hline Severe & 16 & 30.8 & 6 & 4.8 & 2 & 8.3 & \\
\hline
\end{tabular}


by Takeda et al., ${ }^{30}$ the authors reported that over one-third of RA patients demonstrated a high anxiety level. Zyrianova et al. ${ }^{31}$ detected that $65 \%$ of their patients with RA had depression $(37.5 \%$ moderate or severe) and $44.4 \%$ had anxiety $(17.8 \%$ moderate or severe). Furthermore, Isik et al. ${ }^{32}$ found that total prevalence of anxiety, depression, and mixed anxiety-depressive disorder was $70.8 \%$ in patients with RA (of these, $41.5 \%$ had depression, 13.4\% had anxiety, and 15.9\% had mixed anxiety-depressive disorder) and $7.3 \%$ in the control group. Mella et al. ${ }^{33}$ demonstrated that in patients with RA, the prevalence of depression and anxiety symptoms were $53.2 \%$ and $48.4 \%$, respectively. Cross sectional and comparative studies in RA reported that age, RA duration, RA activity, morning stiffness, physical disability, functional disability, pain, fatigue, social stress, marital status, worries about partner interest are key predictors of clinical depression. ${ }^{11,12,27,28,30-34}$

Sexual function is closely related to satisfactory quality of life. According to the World Health Organization, sexual health is closely associated with physical, emotional, mental and social aspects of well-being in relation to sexuality. ${ }^{35}$ We reported that nearly $4 \%$ to $77.8 \%$ of patients experienced sexual problems including sexual disability and loss of sexual desire and satisfaction which vary with age, duration of RA, degree of physical disability, pain, and psychiatric comorbidity. ${ }^{13}$ Previous studies reported sexual problems in 30\% to $76 \%$ of patients with RA. ${ }^{5,13}$ Other studies revealed that $\sim 50 \%$ of patients with RA experienced loss of sexual interest and 60\% were unsatisfied with their sexual quality-of-life. In the study of Kobelt et al., ${ }^{36}$ the authors reported that age, sex, living alone, physical function and mood were significant predictors for being sexually active in patients with RA while age and overall quality of life were the significant predictors for being sexually active in control subjects. Moreover, Coskun et al. ${ }^{37}$ reported worse sexual functioning in females with RA lassessed by Female Sexual Function Index (FSFI)] which involved desire $(p=0.0001)$, arousal $(p=0.0001)$, lubrication $(p=0.0001)$, orgasm $(p=0.0001)$, and satisfaction domains $(p=0.022)$ as well as total FSFI scores $(p=0.0001)$, mean BDI scores $(p=0.036)$, and lower quality of life (QoL) which involved physical functioning $(p=0.0001)$, limitations due to physical health $(0=0.0001)$, pain $(p=0.028)$, general health $(p=0.002)$, vitality $(p=0.001)$, and limitations due to emotional problems $(p=0.0001)$ compared with healthy females.

Living with pain, stiffness, fatigue, limited movement and decreased strength associated with arthritis may reduce ability for sexual expression and enjoyment. Moran ${ }^{38}$ reported that in $\sim 35 \%$ to $44 \%$ of patients with RA, the disease put a strain on their relationship, reduced the sexual interest due to limitation of activities and emotional changes, while $\sim 10 \%$ of patients reported that sexual activity was almost or totally impossible. Panush et al. ${ }^{39}$ demonstrated that in $85 \%$ of their patients, the increased disease activity with joint swelling was a major limiting factor for initiating sexual activity. Furthermore, Shahar et al. $^{40}$ showed significant correlation between sexual function index score (assessed by Malay Version of FSFI) with erythrocyte sedimentation rate $(\mathrm{r}=-0.364, \mathrm{p}=0.009)$ and disease activity score in 28 joints $(r=-0.268, p=0.057)$, patient's age $(r=0.520, p<0.001)$, duration of marriage $(r=-0.355, p=0.001)$, husband's age $(r=-0.460$, $p=0.001)$, age of oldest child $(r=-0.449, p=0.001)$, and age of youngest child $(\mathrm{r}=-0.627, \mathrm{p}<0.001)$. Yilmaz et al. ${ }^{41}$ reported a strong negative correlation between total female sexual function score with disease activity scores in 28 joints, a moderate negative correlation between total female sexual function score with $\mathrm{HAQ}, \mathrm{BDI}$, visual analog scale scores, age, and morning stiffness and weak negative correlation between total female sexual function score and body mass index in females with RA. Hari et al. $^{42}$ demonstrated higher percentage of sexual dysfunction (assessed by FSFI) in females with RA which involves all dimensions of sexuality including desire, arousal, lubrication, orgasm, and satisfaction except pain. In multivariate linear regression analysis, the authors reported that swollen joints and disease activity were the independent variables associated with sexual dysfunction. In the multivariate analysis of this study, we observed that sexual disability and loss of sexual desire or satisfaction were significantly associated with physical dysfunction and psychiatric comorbidities such as depression, but not with disease activity or pain. In accordance, Costa et al. ${ }^{43}$ reported higher percentage of sexual dysfunction (assessed by FSFI) in females with RA (79.6\%); however, they showed no association of disease activity 
or functional disability with sexual dysfunction. Arthritis results in restriction of normal activities and might distort self-image, self-perception and self-esteem resulting in depression and anxiety and thus reluctance to share physical relationship with someone. Anxiety has been highly associated with depression in several studies.

There are some limitations of this study. First, the sample included patients with severe disease stage and longer disease duration and none were on biological treatment of RA. Thus, the results may not reflect the general population of RA. Second, we conducted a cross-sectional study which is less valuable than prospective studies. Third, we used the Health Assessment Questionnaire Disability Index to assess sexual function which is less sensitive than self-rating FSFI. This may be explained by the fact that patients were illiterate (i.e. applying self-rating FSFI would not be possible) and the reluctance of patients to mention their sexual problems to clinicians because of restricted cultural factors.

In conclusion, the results of this study indicate that sexual health in females with RA may be improved with a multidisciplinary approach including rheumatologists, physiotherapists, orthopedists, and psychiatrists with both pharmacological interventions to reduce disease activity and pain and non-pharmacological interventions to improve the patient's quality of life. The frequency rates of sexual problems in females with RA are high and particularly related to physical disability and psychiatric comorbidities. We hope that this information offers recommendations for clinical practice.

\section{Declaration of conflicting interests}

The authors declared no conflicts of interest with respect to the authorship and/or publication of this article.

\section{Funding}

The authors received no financial support for the research and/or authorship of this article.

\section{REFERENCES}

1. Alamanos Y, Drosos AA. Epidemiology of adult rheumatoid arthritis. Autoimmun Rev 2005;4:130-6.

2. Chopra A, Abdel-Nasser A. Epidemiology of rheumatic musculoskeletal disorders in the developing world. Best Pract Res Clin Rheumatol 2008;22:583-604.

3. Elst P, Sybesma T, van der Stadt RJ, Prins AP, Muller $\mathrm{WH}$, den Butter A. Sexual problems in rheumatoid arthritis and ankylosing spondylitis. Arthritis Rheum 1984;27:217-20.

4. Rosenbaum TY. Musculoskeletal pain and sexual function in women. J Sex Med 2010;7:645-53.

5. Abdel-Nasser AM, Ali EI. Determinants of sexual disability and dissatisfaction in female patients with rheumatoid arthritis. Clin Rheumatol 2006;25:82230.

6. Gerosa M, De Angelis V, Riboldi P, Meroni PL. Rheumatoid arthritis: a female challenge. Womens Health (Lond Engl) 2008;4:195-201.

7. Areskoug-Josefsson K, Oberg U. A literature review of the sexual health of women with rheumatoid arthritis. Musculoskeletal Care 2009;7:219-26.

8. Tristano AG. The impact of rheumatic diseases on sexual function. Rheumatol Int 2009;29:853-60.

9. Josefsson KA, Gard G. Women's experiences of sexual health when living with rheumatoid arthritis-an explorative qualitative study. BMC Musculoskelet Disord 2010;11:240.

10. Kovacs WJ, Olsen NJ. Sexual dimorphism of RA manifestations: genes, hormones and behavior. Nat Rev Rheumatol 2011;7:307-10.

11. Pincus T, Griffith J, Pearce S, Isenberg D. Prevalence of self-reported depression in patients with rheumatoid arthritis. Br J Rheumatol 1996;35:879-83.

12. Wright GE, Parker JC, Smarr KL, Johnson JC, Hewett JE, Walker SE. Age, depressive symptoms, and rheumatoid arthritis. Arthritis Rheum 1998;41:298-305.

13. Hill J. The impact of rheumatoid arthritis on patients' sex lives. Nurs Times 2004;100:34-5.

14. Arnett FC, Edworthy SM, Bloch DA, McShane DJ, Fries JF, Cooper NS, et al. The American Rheumatism Association 1987 revised criteria for the classification of rheumatoid arthritis. Arthritis Rheum 1988;31:315-24.

15. Mallya RK, Mace BE. The assessment of disease activity in rheumatoid arthritis using a multivariate analysis. Rheumatol Rehabil 1981;20:14-7.

16. Ramey DR, Raynauld JP, Fries JF. The health assessment questionnaire 1992: status and review. Arthritis Care Res 1992;5:119-29.

17. Helland Y, Dagfinrud H, Kvien TK. Perceived influence of health status on sexual activity in RA patients: associations with demographic and disease-related variables. Scand J Rheumatol 2008;37:194-9.

18. McCaffery M, Beebe A. Pain: Clinical Manual for Nursing Practice. Baltimore: Mosby Company; 1993.

19. Derogatis LR, Morrow GR, Fetting J, Penman D, Piasetsky S, Schmale AM, et al. The prevalence of psychiatric disorders among cancer patients. JAMA 1983;249:751-7. 
20. American Psychiatric Association. Diagnostic and Statistical Manual of Mental Disorders, 4th ed. Washington: American Psychiatric Association; 1994. p. 317-91.

21. Gharyb AG. Beck Depression Inventory-II (BDIII), Arabic Examiner's Handbook. Dar El-Anglo Publishing, Egypt, Cairo; 2000.

22. Beck AT, Steer RA, Ball R, Ranieri W. Comparison of Beck Depression Inventories -IA and -II in psychiatric outpatients. J Pers Assess 1996;67:588-97.

23. Spielberger CD, Gorsuch RL, Lushene RE. Manual for the State-Trait Anxiety Inventory. Palo Alto, CA: Consulting Psychologists Press; 1970.

24. Ambler N, Williams AC, Hill P, Gunary R, Cratchley G. Sexual difficulties of chronic pain patients. Clin J Pain 2001;17:138-45.

25. van Berlo WT, van de Wiel HB, Taal E, Rasker JJ, Weijmar Schultz WC, van Rijswijk MH. Sexual functioning of people with rheumatoid arthritis: a multicenter study. Clin Rheumatol 2007;26:30-8.

26. Badley EM. The impact of disabling arthritis. Arthritis Care Res 1995;8:221-8.

27. Katz PP, Yelin EH. Prevalence and correlates of depressive symptoms among persons with rheumatoid arthritis. J Rheumatol 1993;20:790-6.

28. Sharpe L, Sensky T, Allard S. The course of depression in recent onset rheumatoid arthritis: the predictive role of disability, illness perceptions, pain and coping. J Psychosom Res 2001;51:713-9.

29. el-Miedany YM, el-Rasheed AH. Is anxiety a more common disorder than depression in rheumatoid arthritis? Joint Bone Spine 2002;69:300-6.

30. Takeda T, Morimoto N, Kinukawa N, Nagamine R, Shutou T, Tashiro N. Factors affecting depression and anxiety in female Japanese patients with rheumatoid arthritis. Clin Exp Rheumatol 2000;18:735-8.

31. Zyrianova Y, Kelly BD, Gallagher C, McCarthy C, Molloy MG, Sheehan J, et al. Depression and anxiety in rheumatoid arthritis: the role of perceived social support. Ir J Med Sci 2006;175:32-6.
32. Isik A, Koca SS, Ozturk A, Mermi O. Anxiety and depression in patients with rheumatoid arthritis. Clin Rheumatol 2007;26:872-8.

33. Mella LF, Bértolo MB, Dalgalarrondo P. Depressive symptoms in rheumatoid arthritis. Rev Bras Psiquiatr 2010;32:257-63.

34. Geerlings SW, Beekman AT, Deeg DJ, Twisk JW, Van Tilburg W. Duration and severity of depression predict mortality in older adults in the community. Psychol Med 2002;32:609-18.

35. Sexual health document series Geneva. World Health Organisation; 2006. p. 35.

36. Kobelt G, Texier-Richard B, Mimoun S, Woronoff AS, Bertholon DR, Perdriger A, et al. Rheumatoid arthritis and sexuality: a patient survey in France. BMC Musculoskelet Disord 2012;13:170.

37. Coskun B, Coskun BN, Atis G, Ergenekon E, Dilek $\mathrm{K}$. Evaluation of sexual function in women with rheumatoid arthritis. Urol J 2014;10:1081-7.

38. Moran MG. Psychiatric aspects of rheumatology. Psychiatr Clin North Am 1996;19:575-87.

39. Panush RS, Mihailescu GD, Gornisiewicz MT, Sutaria $\mathrm{SH}$, Wallace DJ. Sex and arthritis. Bull Rheum Dis 2000;49:1-4.

40. Shahar MA, Hussein H, Sidi H, Shah SA, Mohamed Said MS. Sexual dysfunction and its determinants in Malaysian women with rheumatoid arthritis. Int J Rheum Dis 2012;15:468-77.

41. Yilmaz H, Polat HA, Yilmaz SD, Erkin G, Kucuksen $S$, Salli $A$, et al. Evaluation of sexual dysfunction in women with rheumatoid arthritis: a controlled study. J Sex Med 2012;9:2664-70.

42. Hari A, Rostom S, Lahlou R, Bahiri R, HajjajHassouni N. Sexual function in Moroccan women with rheumatoid arthritis and its relationship with disease activity. Clin Rheumatol 2015;34:1047-51.

43. Costa TF, Silva CR, Muniz LF, Mota LM. Prevalence of sexual dysfunction among female patients followed in a Brasília Cohort of early rheumatoid arthritis. Rev Bras Reumatol 2015;55:123-32. 